\title{
The Vocational and Psychological Guiding and Counseling Needs of Students at Al-Balqa Applied University
}

\author{
Mufadi Al- Momani ${ }^{1}$, Nayef Fadous Alhamad ${ }^{2}$ \& Abed Al-Nasser A. Al-Azam ${ }^{3}$ \\ ${ }^{1}$ Department of Education, Al-Balqa Applied University, Jordan \\ ${ }^{2}$ Department of Education, Al-Balqa Applied University, Jordan \\ ${ }^{3}$ Department of Education, Al-Balqa Applied University, Jordan
}

Correspondence: Mufadi Al- Momani, Associate professor, Department of Education, Al-Balqa Applied University, Irbid, Jordan.

Received: April 2, 2018 Accepted: April 16, 2018 Online Published: May 15, 2018

doi:10.5539/res.v10n2p175 URL: https://doi.org/10.5539/res.v10n2p175

\begin{abstract}
The study aims to expose the vocational and psychological guiding and counseling needs of students at Al-Balqa' Applied University (BAU), and the study tool was implemented; after confirming the sincerity and stability of it, which consists of (60) articles, that represents the vocational and psychological guiding and counseling needs for its sample of (291) BAU students for the second semester of the academic year (2016-2017). The study results showed that level of vocational and psychological guiding and counseling needs of students at BAU is medium, where (28) articles of needs came at high level, while (32) came at medium level. It showed the existence of statistically significant difference at $(\alpha=0.05)$ level between the arithmetic means of study sample members estimation on the articles of vocational and psychological guiding and counseling needs scale, as a whole, due to the sex variable of female, and the existence of statistically significant difference at $(\alpha=0.05)$ level between the arithmetic means of study sample members estimation on the articles of vocational and psychological guiding and counseling needs scale, as a whole, due to the study phase variable of diploma compared with the bachelor degree, and it also showed the existence of statistically significant difference at $(\alpha=0.05)$ level between the arithmetic means of study sample members estimation on the articles of vocational and psychological guiding and counseling needs scale, as a whole, due to the major variable of humanity and occupational compared with the science major.
\end{abstract}

Keywords: Al-Balqa' Applied University (BAU) students, psychological guiding and counseling needs, vocational guiding and counseling needs

\section{Introduction}

The world goes through cultural, technological, and educational changes and developments, since the beginning of the 21 st century, which affects all aspects of life, such as economical, social, educational, especially the university education, therefore the importance of identifying vocational and psychological guiding and counseling needs arose for the University students, as an urgent need to help universities' students face the challenges that posed by the educational quality and labor market requirements (Rida, 2006; Al-Dulaim, 2011), where the University mainly; participate in building the student personality through providing advance and developed curriculums, and by providing the human relations and social interactions, while the student personality develops and shows during the University preparation period, which reveals the students prospective, directions, values, and mental abilities, in addition to their multiple needs and motives (Kolone, Scanlan, Karen, and Christine, 2006).

University students considers the backbone of nation and the foundation of its advancement and development, where building and developing the society rest on their shoulders and lies upon them, and caring about this element and paying attention to them considers of great importance, since the process of preparing and rehabilitating them is the foundation for building society and its distinction, especially the students of technical and vocational majors, where the world turns today to the process of vocational education, due to increase in unemployment rates in the world, especially in the non-developing countries, where the political and governmental plans always refer to the interest in vocational and technical education and encourage its followers (Fogel \& Melson, 2004).

The student's personality cultivates and refines during the university period, and this includes student prospective, directions, needs, and multiple motives, also the stable social conditions provide wider opportunities to achieve a high 
level of achievement and ambition, and satisfy the basic needs of individuals, not to mention that current culture and evolution circumstances plays a large role in satisfying the individual needs, therefore the non-developed societies cares continuously about satisfying the physiological and security needs more than satisfying the other needs of its members, while the developed societies cares about satisfying the self-actualization needs (Galassi \& Akos, 2012), and Maslow sees that distress and frustration about dissatisfaction of the need is the main factor in the personality growth lack of integration, and is also the main reason for the occurrence of abnormalities or defects types in the formation of individual personality through his life (Al-Swailem, 2002 \& Morsi, 1997).

College students at this stage have a real need to discover themselves, achieve independency and personal identity, prove themselves, and gain the social and vocational status they aim to achieve, and all of that puts them in the face of vocational and psychological guiding and counseling needs (Hatch, 2008), which they may fail to meet and satisfy due to their study duties and homework's, and the problems they face in the fields of family, social, economic, or future planning, where the university educational system considers directly responsible for the development and refinement of student's personality, and satisfy those needs (Tashtoush, 2012 \& Al-Tahan, and Abu-Eietah, 2002).

The student in the university stage characterized by clear and continuous growth in maturity, in the various aspects of personality, such as mental, emotional, and social (Mansi \& Mansi, 2004), gain the social behavioral standards, social independence and carry the self responsibility, create social relationships, the ability to make decisions; in regard to education and occupation, and bear the responsibility of guiding themselves by knowing the abilities and potential, and ability to think independently and plan for their future (Sanatos, 2003).

Needs consider one of the most important concepts, and it's the subject of human being; in all its diverse and renewable requirements and aspects according to the interim changes and the changes of time, besides that human considers exceptional creature and social individual (Al-Shawi, 2012), and the needs reflect itself through the apparent behavior, and in case those needs weren't satisfy, the individual then becomes in a situation that leads to tension, and thus his balance breaks down, then we can say that an individual has a problem, and the need is a situation that leads to instability of human being, and destabilizing its balance, which leads to consult the motivation, and the motivation is the driving force of behavior, in order to get the need satisfied, rebalance, and remove the tension (milhem, 2007\& Al-Dulaim, 2011).

The guiding and counseling needs are achieving the alignment between personality aspects, in order to reach the best level of physical and mental health, which is the desire to express the problems in a positive organized manner to satisfy the physiological or psychological needs, that students weren't prepared to satisfy by themselves, either because it's undiscovered or discovered but not satisfied, and in both cases the students need organized counseling and tutoring services to satisfy their needs, and get rid of the problems, to be able to interact with the surrounding environment and adapt to it (Al-Swailem, 2002\& Al-Hakamani, 2008).

The guiding and counseling needs of students means students' desire to express their problems in a positive organized manner, for the purpose of satisfying the needs that students weren't prepared to satisfy, either because they didn't discover it themselves, or they discovered it but couldn't satisfy it or get rid of it, and also their desire to have the ability to interact with their environment and adapt to the society that they lives in (Erford, House, \& Martin, 2011). (Kaufman, 1972) identified needs as the end result from the contradiction between what really exists and what it should be, and (Good, 1973) identified the guiding and counseling needs as the demands for human beings survival, continuity of their growth, health, social acceptance, and the alignment between the social personality aspects, in order to reach the best level of health.

Therefore, the guiding and counseling need is the desire of students to express their problems in a positive organized manner to satisfy the physiological or psychological needs, that students weren't prepared to satisfy by themselves, either because it's undiscovered or discovered but not satisfied, and in both cases the students need organized counseling and tutoring services to satisfy their needs, and get rid of the problems, to be able to interact with the surrounding environment and adapt to the society that they lives in (Al-Swailem, $2002 \&$ Morsi, 1997).

Therefore, we recognize the importance of searching for the vocational and psychological guiding and counseling needs, as problems which students feel, work to alleviate its effects on their academic achievements, achieve their academic and psychological adaptation, and proceed in their academic and vocational studies. 


\section{Study Importance}

This study derives its significance from the theoretical and practical aspects:

\subsection{Theoretical Importance}

1. The importance of guiding and counseling needs for university students, the method used to deal with their problems and alleviate its effects on their mental and psychological health, and their self alignment, as much as possible, to walk with strong and confident steps toward the academic success and scientific excellence or educational and vocational planning. It's no doubt that the University significantly contribute to build student personality, by providing advanced and developed curriculums, and also providing social interaction and human relationships.

2. The university considers a formation and preparation stage of personality, with all its personal, mental, psychological, and social components, and it's the stage where university students face multiple problems, in the various fields, such as the vocational and psychological, which requires finding the appropriate solutions for it.

3. The guiding and counseling needs considers one of the most important educational issues that related to mental health and psychological counseling, due to their special importance of bringing benefit to the students, through helping them satisfying their needs, and achieving the psychological and cognitive alignment, on one hand and strengthen their potentials and upgrading it to a high level of perfection, on the other hand.

\subsection{Practical Importance}

1. Satisfying the vocational and psychological needs of students, considers one of the most important needs for them, with the fact that some of them are unable to select the appropriate major of study, or psychologically adopt with this academic major, and select the future career.

2. Paying attention to the vocational and psychological guiding and counseling needs, which help students assess their preparations, and identify the weak and strong points, by identifying the professional expertise, achieving the professional alignment, and helping the students to decide on their ultimate career, and here it shows the importance of meeting the vocational guiding and counseling needs that helps them gain the right psychological growth.

3. The results of this study consider as a consultation for planning the guiding programs to achieve the vocational and psychological success, and employ the guiding and counseling methods, by holding the seminars and conferences.

4. This study puts in front of the University officials, a comprehensive vision and view for the guiding service levels; where it teach students the vocational and psychological guiding and counseling needs, therefore it will provide database that help student affair officials at the university to expand their guiding and counseling services, thus achieving an integrated development for the university students.

\section{Study Problem}

University students represent an important and supplementary dimension for the society, where they carry responsibilities relate to their future and the future of the country in general, in addition to carrying the personal and social responsibilities in the future. Most university students suffer from the problems they face, after moving from high school to the university stage related to non- satisfaction of professional and psychological needs, which increase since it consider part of the educational program, therefore students are in need of help to improve and promote the guiding and counseling services provided for them, in order to move towards success.

The followers of student issues at the university stage, find them deeply in need of vocational and psychological guiding and counseling, where the majority of them didn't think about selecting their major of study, but believes that selecting major is a difficult matter, and those students who selected a major, you will find them selected an area that didn't align with their preferences and abilities, therefore if those students graduated from the university and entered the job market, you will find them deal with their job without creativity or perfection, or find them work in a field differ from their field of study, which reflect the mental health of students.

\section{The Study Problem Can be Summarized in the Following Two Questions:}

-What is the level of vocational and psychological guiding and counseling needs of BAU students?

- Are there any statistically significant differences at level $(\alpha=0.05)$ between the arithmetic means of study sample members' estimations, on the measurement articles of vocational and psychological guiding and counseling as a whole, due to the variables of sex, major of study, and study period? 


\section{Study Objectives}

The current study aims to identify the guiding and counseling needs of students, in order to provide the appropriate psychological guiding and counseling services for them and reach the main goals of the educational and teaching process represented in achieving the psychological and vocational alignment, and the academic success, and the study aims specifically to:

1. Identify the vocational and psychological guiding and counseling needs of BAU students, according to their point of view.

2. Are the professional and psychological guiding and counseling needs among students differ, by sex, major of study, and study stage?

\section{Previous Studies}

(Nicole, 2015) did a study about career counseling sessions method and counselors' preparation, and its effects on career readiness enhancement, and Delphi's method was used to make an agreement between a group of experts about how to prepare school counselors to provide the professional advice before the service, and promote and measure their career readiness in their work with students at all grade levels. The study arrived to a general level of agreement at (79.7), the factors were compared and disagreed with (12) professional practice.

But (Abulaish,2014) did a study that aims to identify the counseling needs of students at the faculty of education, University of Hail, and their relationship to the social situation, major of study, place of living. The results indicated that the sequence of students' needs, according to the point view of female students in the four areas of study were as follow: professional needs, academic needs, psychological needs, and social needs, and the results also showed non-existence of statistically significant differences between the average grades of students, in relation to their counseling needs, according to the variables of social situation, major of study, and place of living.

While (Donohue, 2014) performed a study about executing the interventions and the positive behavioral support of school: school counselors' perceptions about the outputs (student, school climate, and professional effectiveness), and positive behavior support program at the school level (SWPBIS).This study aims to understand the perceptions of educational counselors in the middle and high schools levels about the impact of this system. The results of the study showed in the opinion of experienced school counselors in the schools that implemented the positive behavior support program, who emphasize there are changes that have been identified on students results, school climate, and the resulted effects of school counselors' effectiveness, where it provide proposals and suggestions to the school counselors and school counseling curriculums, based on the results of this study.

The study of (Al-Shawi, 2012), aimed to identify the counseling needs of female students at the physical education college, identify the level of academic achievement motivation for female students, and also identify the relationship between the academic achievement motivation and consulting needs. The study found that level of consulting needs (educational, psychological, social, economical, health, and leisure time) are high among the female students of the physical education college, the level of academic achievement motivation among the female students is also high, and there is a correlation between the academic achievement motivation and the consulting needs.

Where Al-Reweily (2010) did a study that aimed to identify the availability level of consulting needs at the technical colleges in Saudi Arabia, according the students. The study results showed that availability level of consulting needs in the technical colleges of Saudi Arabia came within a low estimation degree, the social needs came in the first rank, followed by professional, then academicals, and psychological came in the last place, and there are differences in the availability level of consulting needs, due to the difference between the categories in the sex variable, and in favor of male, and there are also differences due to the different school district variable levels.

And (Al- Hakamani, 2008) held a study that aimed to reveal the consulting needs, from the perspective of private University students at the Sultanate of Oman, and the study results showed that consulting needs fields came in the following order: academic, psychological, occupational, and social, and also showed a non-existence of differences that could be attributed to the following variables: sex, University, academic year, except in the area of social needs, where it showed differences for the second year, and the accumulative average variable.

Where the study of (Nuri \& Yahiya, 2008) aimed to identify the psychological,

Social and academic consulting needs of students at Mosul University, and identify the significant statistical differences of consulting needs, according to the variables of sex and study year. The study results concluded there are sharp consulting needs, where six of them are academic, psychological, and social, and showed significant differences in the psychological, social, and academic needs between males and females in general, and the results also showed significant differences between students in the consulting needs, according to their study period. 
But (Kolone, Scanlan, Kolone, Pantzer, and Christine,2006) targeted in their study the discovery of relationship between career decision making self-efficiency, professional identity, and career exploration and behavior among the African American high school students. The results indicated that highest levels of self-efficiency in career decision making, is more linked to the concept of vocational excellence and the excessive effectiveness with the career exploration activities, and also discussed in the study the implications of vocational guiding and the future researches.

While the study of (Al-Riashi, 2004) aimed to recognize the consulting needs of community colleges, and vocational institutes and colleges, and proposed methods to satisfy them. The results of the study showed that students of community colleges, and vocational institutes and colleges have consulting and guiding needs, where the religious consulting needs came first, followed by academic, psychological, social, and health; in that order, then came the economical consulting in the last place, and turned out the existence of statistically significant differences among students of community colleges, and vocational institutes and colleges in the fields of academic, health, economic, religious, and leisure time, while it didn't show any statistically significant differences in the psychological and social field.

In the study of (Al-Osfoor, 2004), the researcher aimed to examine the nature and type of consulting needs of secondary school students at Muscat and interior regions in the Sultanate of Oman. The study results indicated that most important consulting needs of students are: work to improve the academic grades of students, gain parental confidence, develop the academic capabilities and potentials, and learn study time organizing methods. The results explained the sequences of these consulting needs, where the academic came first, followed by professional, psychological, family, and social needs came last, and the results also found statistically significant differences between sexes, in the consulting needs, in favor of females.

\section{Study Procedures}

\subsection{Study Population and Sample}

The study population consists of students at BAU, for the second semester of the academic year (2016-2017), and the study sample selected randomly, from students of Irbid university college, and Huson university college, which amounted to (291) male and female students, and table (1) shows the study sample members characteristics, according to its distribution by sex, major of study, and study period:

Table 1. Distribution of study sample members, according to sex, major of study, and study period variables

\begin{tabular}{l|l|l|l}
\hline Variable & Level/ Category & Quantity & $\%$ \\
\hline \multirow{4}{*}{ Sex } & Male & 146 & 50.2 \\
& Female & 145 & 49.8 \\
& Total & 291 & 100.0 \\
\hline \multirow{5}{*}{ Major of study } & Academic & 99 & 34.0 \\
& Human & 125 & 43.0 \\
& Vocational & 67 & 23.0 \\
& Total & 291 & 100.0 \\
\hline & Bachelor degree & 148 & 50.9 \\
& Diploma degree & 143 & 49.1 \\
& Total & 291 & 100.0 \\
\hline
\end{tabular}

\subsection{Study Methods \& Tools}

The measurement of psychological and professional guiding and consulting needs:

To achieve the goal of the current study, the researchers developed a measurement for the psychological and professional guiding and consulting needs, and this measurement consists of two parts: the first one contain the primary information, such as sex, major of study, and study period, and the second contain (59) paragraphs, where the answer for each paragraph, according to the Likert five scale method dealt with the five following levels, which are feeling the need with a very high degree, high degree, normal degree, low degree, and not feeling the need, and also gave scores ranging from 5 for the "very high degree" and1for "not feeling the need". 


\subsection{Study Tool Design Procedures}

The researchers designed a measurement for the professional and psychological guiding and consulting needs, based on the following:

- Review the theoretical literatures and previous studies related to study topic.

- View a number of scales and measurements in previous studies.

- Survey students' opinions, by asking them an open question about the professional and psychological needs and problems they face at the University.

- Researchers have the experience and knowledge about students professional and psychological consulting needs, sense they are instructors at the university.

- According to the previous steps, the scale and measurement designed in its initial way to (62) paragraphs.

- Checked and validated the scale sincerity, by representing it to the arbitrators.

- The scale was implemented on the students.

\subsection{External Sincerity}

To verify the sincerity indicators of the study tool, it was presented; in its initial image on (4) arbitrators specialized in the educational and psychological counseling, educational psychology, and measurement and evaluation of faculty members working in BAU, and were asked to give their opinions about the tool structure and paragraphs appropriateness, and its clarity level, and in the light of their reviews, remarks, and recommendations, (3) paragraphs were deleted from the scale, where $(80 \%)$ of the arbitrators didn't vote on its appropriateness or clarity, bringing the number of paragraphs in the scale to (59), which arbitrators agreed on its appropriateness to measure the professional and psychological consulting and guiding needs of university students, with (90\%) approval rate.

\subsection{Design Sincerity}

Design and structure sincerity has been verified for the measurement of professional and psychological consulting and guiding needs, through calculating the corrected item-total correlation of each paragraph of the measurement with the measurement as a whole, as shows in table (2) below:

Table 2. the corrected item-total correlation coefficient for each measurement paragraph of the professional and psychological consulting needs with the measurement as a whole

\begin{tabular}{cccccccc}
\hline Number & $\begin{array}{c}\text { Corrected } \\
\text { correlation }\end{array}$ & Number & $\begin{array}{c}\text { Corrected } \\
\text { correlation }\end{array}$ & Number & $\begin{array}{c}\text { Corrected } \\
\text { correlation }\end{array}$ & Number & $\begin{array}{c}\text { Corrected } \\
\text { correlation }\end{array}$ \\
\hline 1 & .41 & 16 & .61 & 31 & .77 & 46 & .64 \\
2 & .42 & 17 & .35 & 32 & .50 & 47 & .35 \\
3 & .47 & 18 & .30 & 33 & .50 & 48 & .20 \\
4 & .37 & 19 & .35 & 34 & .60 & 49 & .37 \\
5 & .57 & 20 & .52 & 35 & .69 & 50 & .44 \\
6 & .41 & 21 & .33 & 36 & .78 & 51 & .65 \\
7 & .35 & 22 & .30 & 37 & .75 & 52 & .28 \\
8 & .68 & 23 & .38 & 38 & .66 & 53 & .60 \\
9 & .22 & 24 & .28 & 39 & .77 & 54 & .36 \\
10 & .27 & 25 & .39 & 40 & .24 & 55 & .24 \\
11 & .28 & 26 & .45 & 41 & .49 & 56 & .66 \\
12 & .36 & 27 & .42 & 42 & .62 & 57 & .59 \\
13 & .57 & 28 & .43 & 43 & .28 & 58 & .58 \\
14 & .20 & 29 & .35 & 44 & .37 & 59 & .62 \\
15 & .77 & 30 & .26 & 45 & .39 & & \\
\hline
\end{tabular}

It notices from table (2) that all values of the corrected item-total correlation coefficient greater than $(0.20)$, therefore all values are acceptable for the purpose of this study. 


\subsection{Measurement Consistency of Professional and Psychological Consulting Needs}

To verify the consistency of the study tool, it has been applied on exploratory sample consists of (56) female and male students from the study population and from the outside of it, and then reapplied it on the same sample, with two-week interval between the two cases of implementation, where the coefficient consistency repetition factor (Pearson) amounted to (0.87), while the internal consistency coefficient factor (Alfa Cronbach) amounted to (0.91), which are acceptable values for the purpose of this study.

\subsection{Statistical Criteria for the Measurement of Professional and Psychological Consulting Needs}

To determine the level of professional and psychological consulting needs of BAU students, and for each paragraph of the measurement, statistical criterion has been used, based on the arithmetic means, shown in table (3) below:

Table 3. the statistical criteria to determine the level of professional and psychological consulting needs of BAU students as a whole, and for each paragraph of the measurement based on the arithmetic means

\begin{tabular}{c|c}
\hline Arithmetic means & Level \\
\hline From $1.00-$ less than 1.80 & Very low \\
\hline From $1.80-$ less than 2.60 & Low \\
\hline From $2.60-$ less than 3.40 & Medium \\
\hline From $3.40-$ less than 4.20 & High \\
\hline From $4.20-5.00$ & Very high \\
\hline
\end{tabular}

\subsection{Study Variables}

The study included the following variables:

a) Independent variables, and included:

- Sex: with two categories (Male, Female).

- Major of study: with three categories: (Academic, human, vocational).

- Study period: with two levels (Diploma, Bachelor).

b) Dependent variable: it includes the level of professional and psychological consulting needs of BAU students as a whole, which represented by the arithmetic mean of study sample members estimations on the measurement paragraph of professional and psychological consulting needs.

\subsection{Study Design}

The descriptive approach has been used, due to its scientific steps that examine the professional and psychological consulting and guiding needs of students and its relationship with the studied variables, and then analyze, explain, and interpret that information, and arrive to the results, which can contribute to the achievement of study goals.

\subsection{Study Terms and its Procedural Definitions}

- Consulting and guiding needs: It's the needs that University student finds it necessary to assist them in solving their problems, and divided into professional and psychological needs related to different aspects of student life, such as identifying their personal preparations and readiness, measuring their trends, tendencies, and interests, and their general capabilities, in addition to helping them select major of study or appropriate career for their future job, which they aren't qualify to satisfy it on their own, but needs specialized assistance to satisfy it and achieve the academic and psychological adaptation (Al-Swailem, 2002, milhem, 2007), and here a brief definition for the professional and psychological needs:

- Professional needs: it's the needs that students find necessary, to help them identify major of study and professional field, vocational interests, capabilities to determine the major of study, and their relationships to select the future career, in order to adapt wisely with the future profession that right for them.

- Psychological needs: it's a group of natural desires that work to achieve the balance, stability, and life constancy of individuals, and it's the psychological nature needs, which students see a need to meet them, to help them solve the problems related to the psychological nature and satisfy it, in order to achieve the personal and psychological balance, overcome the emotional conflict, build the successful social relationships with others, and reach deeper understanding of themselves (Morsi, 1997). 


\subsection{Statistical Processes}

The arithmetic means and standard deviations were used to answer the first question of the study, to find out the level of professional and psychological consulting and guiding needs of BAU students, as the study sample members, and to answer the second question, the arithmetic means and standard deviations, according to the variables of sex, major of study, and study period, and also perform (Three way ANOVA) analysis to identify the statistical significance of external differences between the arithmetic means, for the estimations of study sample members on paragraphs measurement of the professional and psychological consulting and guiding needs as a whole, according to the variables of sex, major of study, and study period.

\section{Study Results}

\subsection{Results Display}

The results of first question which stated: What is the level of vocational and psychological guiding and counseling needs of BAU students?

The arithmetic means and standard deviations were used to answer the above question, for the estimations of study sample members on paragraphs measurement of the professional and psychological consulting and guiding needs as a whole, and all of its paragraphs, as shows in table (4) below:

Table 4. The arithmetic means and standard deviations, for the estimations of study sample members on paragraphs measurement of the professional and psychological consulting and guiding needs as a whole, and all of its paragraphs, organized in descending order according to the arithmetic means

\begin{tabular}{|c|c|c|c|c|c|}
\hline Number & Paragraph & $\begin{array}{c}\text { Arithmetic } \\
\text { mean }\end{array}$ & STDEV & Rank & Level \\
\hline 38 & The need to open the required majors by labor market & 4.16 & 0.92 & 1 & High \\
\hline 47 & $\begin{array}{l}\text { I need someone to help me clarify the relationship between } \\
\text { major and professions associated with it }\end{array}$ & 4.08 & 0.91 & 2 & High \\
\hline 37 & $\begin{array}{l}\text { Provide no technical and vocational advices for student, and } \\
\text { indirect them to the recruitment sources }\end{array}$ & 4.07 & 0.95 & 3 & High \\
\hline 40 & I feel an inability for time management & 4.03 & 1.06 & 4 & High \\
\hline 48 & $\begin{array}{l}\text { I need someone help to inform me about the required } \\
\text { professions in labor market }\end{array}$ & 4.01 & 0.99 & 5 & High \\
\hline 50 & Lack of proper professional majors for both sexes & 4.00 & 0.95 & 6 & High \\
\hline 42 & I find it difficult to achieve my study ambitions & 3.99 & 1.06 & 7 & High \\
\hline 46 & $\begin{array}{l}\text { Non-availability of raw materials in the workshop inside the } \\
\text { University }\end{array}$ & 3.99 & 1.03 & 8 & High \\
\hline 44 & $\begin{array}{l}\text { I selected my major without any information about its } \\
\text { requirements }\end{array}$ & 3.98 & 0.96 & 9 & High \\
\hline 55 & $\begin{array}{l}\text { I didn't find someone to help me select the academic or } \\
\text { vocational major }\end{array}$ & 3.96 & 1.00 & 10 & High \\
\hline 39 & $\begin{array}{l}\text { I don't find anyone to meet my need of measuring directions, } \\
\text { desires, and professional preparations. }\end{array}$ & 3.94 & 0.98 & 11 & High \\
\hline 49 & I feel worried about the future & 3.93 & 0.92 & 12 & High \\
\hline 43 & $\begin{array}{l}\text { I feel insecurity and fear from the future after the graduation } \\
\text { from University }\end{array}$ & 3.88 & 1.08 & 13 & High \\
\hline 57 & $\begin{array}{l}\text { I need someone to help me select the profession that agrees } \\
\text { with my abilities and professional orientations. }\end{array}$ & 3.88 & 1.05 & 14 & High \\
\hline 58 & $\begin{array}{l}\text { I don't have enough information about the professions that } \\
\text { labor market need }\end{array}$ & 3.86 & 1.08 & 15 & High \\
\hline 45 & $\begin{array}{l}\text { Lack of psychological guiding and counseling services at the } \\
\text { university }\end{array}$ & 3.85 & 1.13 & 16 & High \\
\hline 2 & $\begin{array}{l}\text { I suffer lack of cooperation and understanding from the } \\
\text { academic department to solve my study problems }\end{array}$ & 3.84 & 1.09 & 17 & High \\
\hline 41 & $\begin{array}{l}\text { Non-existence of professional training and consulting center at } \\
\text { the university }\end{array}$ & 3.81 & 1.09 & 18 & High \\
\hline 56 & I suffer from dispersion and lack of focus in the study & 3.81 & 1.11 & 19 & High \\
\hline
\end{tabular}




\begin{tabular}{|c|c|c|c|c|c|}
\hline 59 & I suffer from inability to express my opinion freely & 3.81 & 1.09 & 20 & High \\
\hline 52 & I suffer emotion loss of psychological comfort & 3.77 & 1.07 & 21 & High \\
\hline 54 & $\begin{array}{l}\text { It bothers me when one or both of my parents persist and } \\
\text { persuade me to study }\end{array}$ & 3.77 & 1.00 & 22 & High \\
\hline 53 & I have fears whenever test dates approach & 3.76 & 1.07 & 23 & High \\
\hline 51 & I don't find anyone to help me solve my problems. & 3.71 & 1.11 & 24 & High \\
\hline 1 & I have no desire to attend the lectures. & 3.55 & 1.22 & 25 & High \\
\hline 27 & $\begin{array}{l}\text { The University doesn't motivate and support the gifted and } \\
\text { talented students. }\end{array}$ & 3.25 & 1.18 & 26 & High \\
\hline 16 & $\begin{array}{l}\text { I feel that the required courses don't fit with my abilities and } \\
\text { ambitions }\end{array}$ & 3.47 & 1.22 & 27 & High \\
\hline 14 & $\begin{array}{l}\text { Workshops aren't prepare for vocational training inside the } \\
\text { University }\end{array}$ & 3.35 & 1.32 & 28 & Medium \\
\hline 15 & Non-scientific skills development about current study majors & 3.34 & 1.36 & 29 & Medium \\
\hline 10 & $\begin{array}{l}\text { Non-assistance for students in their life and career } \\
\text { professionals affairs }\end{array}$ & 3.33 & 1.28 & 30 & Medium \\
\hline 11 & $\begin{array}{l}\text { I don't have information about the study opportunities in the } \\
\text { future (graduate studies) }\end{array}$ & 3.32 & 1.22 & 31 & Medium \\
\hline 28 & $\begin{array}{l}\text { It's hard to get the required references for some vocational } \\
\text { materials }\end{array}$ & 3.32 & 1.37 & 32 & Medium \\
\hline 23 & I suffer from leisure time spending problem at the university & 3.30 & 1.33 & 33 & Medium \\
\hline 13 & I hesitated when I selected my current major & 3.29 & 1.25 & 34 & Medium \\
\hline 17 & $\begin{array}{l}\text { I need someone to help me increase the resulting knowledge } \\
\text { about appropriate professional aspects for my major }\end{array}$ & 3.29 & 1.29 & 35 & Medium \\
\hline 29 & I feel like I will never find a job after graduation & 3.29 & 1.28 & 36 & Medium \\
\hline 24 & $\begin{array}{l}\text { There are needs for critical facilities for the supplementary } \\
\text { activities inside the University }\end{array}$ & 3.28 & 1.33 & 37 & Medium \\
\hline 18 & I have the desire to change my major & 3.27 & 1.31 & 38 & Medium \\
\hline 22 & $\begin{array}{l}\text { It bothers me that my family doesn't accept my major of } \\
\text { studies. }\end{array}$ & 3.27 & 1.32 & 39 & Medium \\
\hline 21 & $\begin{array}{l}\text { I feel that others don't respect me due to my low cumulative } \\
\text { average (GPA) }\end{array}$ & 3.26 & 1.24 & 40 & Medium \\
\hline 12 & I don't know what to do after graduation from university & 3.21 & 1.29 & 41 & Medium \\
\hline 32 & I feel the fear of making social relationship with others & 3.21 & 1.22 & 42 & Medium \\
\hline 20 & I find it difficult to keep friends inside the University & 3.20 & 1.25 & 43 & Medium \\
\hline 3 & $\begin{array}{l}\text { I feel ashamed and my feelings hurt by the simplest criticism } \\
\text { directed at me }\end{array}$ & 3.18 & 1.18 & 44 & Medium \\
\hline 7 & $\begin{array}{l}\text { The career path I selected doesn't provide me with the job } \\
\text { opportunities in the future }\end{array}$ & 3.16 & 1.32 & 45 & Medium \\
\hline 8 & Lack of specialized instructors in some major courses & 3.16 & 1.26 & 46 & Medium \\
\hline 19 & $\begin{array}{l}\text { I need someone to guide and consult me about the conditions } \\
\text { for changing major of study in accordance with my } \\
\text { preparations and abilities }\end{array}$ & 3.16 & 1.31 & 47 & Medium \\
\hline 5 & $\begin{array}{l}\text { I need the vocational and psychological guiding and } \\
\text { counseling services }\end{array}$ & 3.15 & 1.24 & 48 & Medium \\
\hline 33 & Insufficient field training in my major of study & 3.15 & 1.26 & 49 & Medium \\
\hline 4 & $\begin{array}{l}\text { I didn't select my major based on my orientation, desires and } \\
\text { preparations }\end{array}$ & 3.12 & 1.20 & 50 & Medium \\
\hline 6 & $\begin{array}{l}\text { I don't find someone to meet my need about measuring my } \\
\text { directions and recognize it in the university. }\end{array}$ & 3.12 & 1.37 & 51 & Medium \\
\hline 25 & Lack of specialized instructors in some vocational majors & 3.09 & 1.35 & 52 & Medium \\
\hline 35 & $\begin{array}{l}\text { I suffer from inability to align between my study and social } \\
\text { relationships }\end{array}$ & 3.08 & 1.29 & 53 & Medium \\
\hline 34 & My current major doesn't meet my ambitions & 3.07 & 1.30 & 54 & Medium \\
\hline 9 & I feel ashamed when facing others & 3.06 & 1.33 & 55 & Medium \\
\hline
\end{tabular}




\begin{tabular}{|c|c|c|c|c|c|}
\hline 30 & $\begin{array}{l}\text { It bothers me the lack of required laboratories, workshops, and } \\
\text { training rooms for the study }\end{array}$ & 3.06 & 1.37 & 56 & Medium \\
\hline 31 & I feel anxious, worried, and nervous. & 3.02 & 1.39 & 57 & Medium \\
\hline 26 & I didn't select my major freely and with desire & 3.00 & 1.36 & 58 & Medium \\
\hline 36 & $\begin{array}{l}\text { I feel the lack of reputation, respect, and appreciation with } \\
\text { classmates and instructors }\end{array}$ & 2.80 & 1.25 & 59 & Medium \\
\hline \multicolumn{2}{|c|}{ Measurement as a whole } & 3.08 & 0.97 & & Medium \\
\hline
\end{tabular}

* Lower degree (1) and higher degree (5)

It noticed from table (4) that arithmetic means, for the measurement paragraphs ranged between (2.80) and (4.16) at level (medium) and (high), where paragraph (38) which specified on "The need to open the required majors by labor market", came in the first rank with an arithmetic mean of (4.16) level (high), while paragraph (36), which stated on "I feel the lack of reputation, respect, and appreciation with classmates and instructors" came in last place with an arithmetic mean of (2.80) level (medium). It also showed from the table that the level of professional and psychological consulting and guiding needs, at the sample of BAU students was (medium) with arithmetic mean of (3.08), where (28) paragraphs came with high level while (32) paragraphs came at the medium level.

The results of second question which stated: Are there any statistically significant differences at level $(\alpha=0.05)$ between the arithmetic means of study sample members' estimations, on the measurement articles of vocational and psychological guiding and counseling as a whole, due to the variables of sex, major of study, and study period?

The arithmetic means and standard deviations were used to answer the above question, for the estimations of study sample members on paragraphs measurement of the professional and psychological consulting and guiding needs as a whole, due to the variables of sex, major of study, and study period, as shown in table (5) below:

Table 5. The arithmetic means and standard deviations, for the estimations of study sample members on paragraphs measurement of the professional and psychological consulting and guiding needs as a whole, due to the variables of sex, major of study, and study period.

\begin{tabular}{l|l|c|c}
\hline Variable & Level/ category & Arithmetic mean & STDEV \\
\hline \multirow{4}{*}{ Sex } & Male & 2.82 & 1.02 \\
\cline { 2 - 4 } & Female & 3.34 & 0.85 \\
\cline { 2 - 4 } & Overall & $\mathbf{3 . 0 8}$ & $\mathbf{0 . 9 7}$ \\
\hline \multirow{4}{*}{ Sajor of study } & Academic & 2.73 & 0.98 \\
\cline { 2 - 4 } & Human & 3.16 & 0.93 \\
\cline { 2 - 4 } & Vocational & 3.43 & 0.88 \\
\cline { 2 - 4 } & Overall & $\mathbf{3 . 0 8}$ & $\mathbf{0 . 9 7}$ \\
\hline \multirow{3}{*}{ Study period } & Bachelor & 2.88 & 0.96 \\
\cline { 2 - 4 } & Diploma & 3.28 & 0.95 \\
\cline { 2 - 4 } & Overall & $\mathbf{3 . 0 8}$ & $\mathbf{0 . 9 7}$ \\
\hline
\end{tabular}

It notices from table (5) the existence of external differences between the arithmetic means for the estimations of study sample members on paragraphs measurement of the professional and psychological consulting and guiding needs as a whole, due to sex, major of study, and study period variables, and to identify the statistical significant of these external differences, three way ANOVA analysis was implemented, as shows in table (6) below: 
Table 6. The three way ANOVA analysis for the arithmetic means of study sample members estimations on paragraphs measurement of the professional and psychological consulting and guiding needs as a whole, due to the variables of sex, major of study, and study period

\begin{tabular}{l|c|c|c|c|c}
\hline Variable & SS & DF & MS & F-value & Sig \\
\hline Sex & 12.285 & 1 & 12.285 & $* 14.944$ & 0.000 \\
\hline Major of study & 11.343 & 2 & 5.672 & $* 6.899$ & 0.001 \\
\hline Study period & 5.644 & 1 & 5.644 & $* 6.866$ & 0.009 \\
\hline Error & 235.107 & 286 & 0.822 & & \\
\hline Modified Total & $\mathbf{2 7 5 . 0 1 0}$ & $\mathbf{2 9 0}$ & & & \\
\hline
\end{tabular}

* Statistically significant at the level $(\alpha=0.05)$

It noticed from table (6), the following:

- The value of statistical significance for the sex variable amounted to (0.000), which is lower than the level of statistical significance of $(\alpha=0.05)$ indicating the existence of statistically significant difference at the level $(\alpha=$ 0.05 ) between the two arithmetic means for the estimations of study sample members on paragraphs measurement of the professional and psychological consulting and guiding needs as a whole, due to the variable of sex, and from table (6) the arithmetic means, it shows a statistically significance difference in favor of females.

- The value of statistical significance for the major of study variable amounted to $(0.001)$, which is lower than the level of statistical significance of $(\alpha=0.05)$ indicating the existence of statistically significant difference at the level $(\alpha=0.05)$ between the two arithmetic means for the estimations of study sample members on paragraphs measurement of the professional and psychological consulting and guiding needs as a whole, due to the major of study variable, and to find out in favor of who those statistically significant differences, Scheffe' test for the post hoc comparisons has been used, as it shows in table (7) below:

Table 7. The results of Scheffe' test for the post hoc comparisons arithmetic means for the estimations of study sample members on paragraphs measurement of the professional and psychological consulting and guiding needs as a whole, according to major of study variable

\begin{tabular}{l|l|l|l}
\hline & & The difference between the two arithmetic means \\
\hline Major of study & Arithmetic mean & Human & Vocational \\
\hline Academic (scientific) & 2.73 & $* 0.43$ & $* 0.70$ \\
\hline Human & 3.16 & & 0.27 \\
\hline Vocational & 3.43 & & \\
\hline
\end{tabular}

It notices from table (7) the existence of statistically significant difference between the estimations of study sample members related to the academic majors, in comparison with the humanism and vocational majors, and in favor of individuals estimations for the majors of humanism and vocational.

The value of statistical significance for the study period variable amounted to (0.009), which is lower than the level of statistical significance of $(\alpha=0.05)$ indicating the existence of statistically significant difference at the level $(\alpha=0.05)$ between the two arithmetic means for the estimations of study sample members on paragraphs measurement of the professional and psychological consulting and guiding needs as a whole, due to the study period variable, and from the arithmetic means in table (5), it shows a statistically significance difference in favor of study sample members estimations for the study period (diploma).

\subsection{Study Results Discussion}

7.2.1 Discuss the Results of First Question, Which Stated: What is the Level of Vocational and Psychological Guiding and Counseling Needs of BAU Students?

The results showed that arithmetic means, for the measurement paragraphs ranged between (2.80) and (4.16) at level (medium) and (high), where paragraph (38) which specified on "The need to open the required majors by labor market", came in the first rank with an arithmetic mean of (4.16) level (high), while paragraph (36), which stated on "I feel the lack of reputation, respect, and appreciation from classmates and instructors" came in last place with an arithmetic mean of (2.80) level (medium). It also showed from the table that the level of professional and psychological consulting and 
guiding needs, at sample of BAU students was (medium) with arithmetic mean of (3.08), where (28) paragraphs came at level (high) while (32) paragraphs came at level (medium).

Researchers notices from this result, that professional and psychological needs of the students weren't satisfied or achieved, where it came at a high level, including: The need to open the required majors by labor market, I need someone to help me clarify the relationship between major and professions associated with it, Provide no technical and vocational advices for student, and indirect them to the recruitment sources, I feel an inability for time management, and other vocational, professional, and psychological needs, that combined efforts must be done from the University, family, and society, and they all must seek to fulfill it with the University student.

The researchers see that it's a must to provide students with the consulting services, at all educational levels: elementary school, high school, and colleges and universities, where the vocational and psychological guiding and consulting in universities became associated with any advanced educational system, given that its humanism, social, and educational process, seeks to develop the educational process, raise its efficiency, improve its output, and solve the problems and obstacles that its encounter, according to psychological and educational scientific and academic methods, which adopt the evaluation, assessment, and measurement as a base for it.

In this context, the results of a study by (Guneri et al., 2003), as a college student in one of the Turkish universities, showed that new students expressed their strong need for guiding and consulting service to deal with and solve the academic issues, while students in the higher levels expressed their need to develop searching skills about the job or future career, decision making, and understanding ourselves.

The need to open new majors of study that requires by labor market, came in the first place with an arithmetic mean of (4.16), and at high level between several of the professional and vocational guiding and consulting needs, which researchers see it as logical result, as a result of the job market that suffer from overstocks or piles up of graduate students from the public and private universities, who had a purely theoretical education in the various majors, and particularly humanitarian majors, from one hand and some universities not keeping pace with the needs of labor market in developing new majors required by the labor market, on the other hand, which requires universities to work on developing it and coping with it in their university plans, preparing the laboratories, training, and gaining of students to additional and technical skills, that University didn't prepare its students on it, and this perhaps due to the high cost required by these majors of study, such as building a modern Labs, developing the equipments used in it, or preparing the training workshops that keeps up with the changing labor market, which create a significant financial challenge for universities in the awaking of weak financial support for it, and that what forced many universities to hold on to the old way of teaching, which depends on the theoretical indoctrination, as a key method in education, and not to keep up with the change in the market of different knowledge areas, and that reflected negatively on students ' levels, from the technical and professional aspects, where students will find themselves after graduation, not fit with the needs of labor market (due to poor preparation and training), and because the labor market need a high level mastered and trained skills. Instead of that, many universities are still cranking out large numbers of graduates in majors that soaked the local and regional labor market, especially in the humanity major, therefore youth are no longer find a place to work in these major of studies.

The researchers also see that students are in real need for consulting and guiding services in the professional and vocational field, due to the student's interest in what will wait for them in the future; after graduation, where everyone seek to obtain a job opportunity through the development of their professional expertise, their level of learning and training, their physical and mental abilities, and identify the appropriate working fields that match their abilities, preparations, and readiness.

The researchers see after this result, that identifying those consulting and guiding needs of students and meeting it, contribute to facing the difficulties that could meet them, as well as achieving the psychological and academic adjustment and adaptation, especially since the University message requires to help students cope with their problems, identify their professional and psychological needs, and meet it in a way that contributes to helping students pass the University phase efficiently and skillfully, which reveals the need to pay attention to discover, understand, and analyze the students' innersoles (psyches), deal with their problems, and work to address and solve the problems and disorders that they expose, through addressing those issues, studying the reasons for it, its symptoms, and treatment methods, where these issues of great importance, in terms of their impact on the process of psychological alignment and compatibility, and face the pressures of university life, and therefore its impact on the academic achievement among students.

7.2.2 Discussion of Second Question Results, Which Stated: Are There any Statistically Significant Differences at Level $(\alpha=0.05)$ Between The Arithmetic Means Of Study Sample Members' Estimations, on the Measurement Articles of Vocational and Psychological Guiding and Counseling as a Whole, Due to the Variables of Sex, Major of Study, and Study Period?"

The results showed the existence of statistically significant difference between the two arithmetic means for the 
estimations of study sample members on paragraphs measurement of the professional and psychological consulting and guiding needs as a whole, due to the variable of sex, and in favor of females.

Researchers attribute the need of females to the vocational and psychological consulting and guiding to the nature of prevailing social upbringing in the Arabic culture, which based on the male stereotypes rule, as well as the nature of the emotional side control in the females' behavior, represented in their excessive dependency on others, and the level of extreme protection for them, in addition to the nature of Arabic upbringing in societies, like Jordan doesn't provide the opportunities for females to go out into the job market, engage in it, and view it, as the opportunity provided for males, but males often engage with parents in their businesses, during vacation or leisure times, or go out and work to cover their needs and expenses, which makes them more informed about the labor market needs, and might formulate a vision of what they want to do in the future. They also put the female in a specific work frame, in occupations such as teacher, nurse, or a doctor, and reject any other kind of job for them, while the field is wide open in front of males, in an areas that females don't go near it, such as technical, constructional, professional, industrial, and agricultural areas of work, in addition to the business service areas, such as hotels and restaurants, or even the areas where you may need to work late sometimes.

The results also showed the existence of statistically significant difference between the estimations of study sample members related to the academic majors, in comparison to the humanism and vocational majors, and in favor of individuals estimations for the majors of humanism and vocational.

In regard to the need of humanitarian and vocational majors to the vocational and psychological consulting and guiding needs, researchers believe this caused by the Ministry of education policies, where the Ministry relies on distributing students on the scientific, literary, and vocational streams, depending on their school average grades, where it will assign the highest averages to the scientific field, while the low and averages go to literary and vocational fields, and this reflects the upcoming students fields of university's academic majors, and often students with the highest averages and cleverness, puts for themselves a future plan to select the majors needed by the labor market, while the students with humanitarian majors will go to university majors, that usually saturated and isn't needed, like Arabic language, history, geography, education, sociology, and other stagnant majors, while students of professional and vocational majors go to vocational training centers, and then to the university colleges, which don't focus largely on the practical aspect of education.

The students in the humanity and vocational majors distributed on the academic majors, according to the admissions unit, where their accumulated average, in high school don't let them choose, but within a very limited range of majors, therefore they enroll in the available major for them, according to the admission unit, and perhaps the available majors don't fit with their desires and ambitions, and students only enroll in them to complete the study and get a certificate, without any interest in acquiring the skills that prepare them to engage in the labor market, which makes them in need of psychological and vocational counseling.

The results also showed the existence of statistically significant difference between the two arithmetic means for the estimations of study sample members on paragraphs measurement of the professional and psychological consulting and guiding needs as a whole, due to the study period variable, in favor of study sample members' estimations for the study period (diploma). It also showed the students in the diploma level are in need of psychological and vocational counseling at high degree, and this may explain selecting a major without basing it on the students' ambitions, desires, tendencies, and readiness, inability to align between their studies and their social relationships, inability to organize the time, low grades or accumulated averages, and perhaps the brilliance of acceptable students in the diploma program, who are incapable to choose the appropriate majors for the current scientific and technological development era, and they don't consider themselves competence enough to be perfect, and also they couldn't find anyone to satisfy their needs, measure their trends and directions, and identify it in the University, therefore their needs appeared for the vocational and psychological counseling and guiding services.

Finally, the researchers see that students must go through two stages, the first is psychological exploration stage, meaning to identify all of the passive capabilities in the inner self and its directions, to learn exactly what it want, then it comes the selection stage from the available potentials and opportunities in the society. This will be done by closely identifying all of the vacant jobs or careers, and learn everything we can about its details, in order to get a clear view about this profession, then alignment will be done between the two stages, between the tendencies and capabilities, and the available opportunities, and then comes the appropriate selection.

It also necessary to look for ways that help students select the correct major of study, by hiring a consultant to help students understand the nature of the job and its requirements, and compare that with their personal preferences and tendencies to achieve the best selection, help them to identify and discover their personal skills, abilities, and their superiority points, their decision making methods and regular ways of thinking, and suitable job search skills, identify the work places, and any other necessary skills.

Professional stability at the job, in the future also generally affect the psychological stability of the individuals, where it 
contributes to satisfy the physical and psychological needs, therefore the correct selection of professions and majors prepare the individuals for the psychological alignment, not only in the work field, but in their different aspects of life.

\section{Recommendations}

The study made the following recommendations:

- The importance of providing and satisfying the essential needs, to activate the roles of psychological and professional consulters and guiders, such as vocational and psychological measurement tools, to identify the general and personal capabilities of students, measure their preferences, attitudes, interests, and their social and cultural values.

- Enlighten the students about the available academic majors, its characteristics and the requirements and conditions to register and enroll in it.

- Help students to identify their inclinations, directions, aptitudes, abilities, personalities, and their work related skills.

- Help students to select the academic and scientific majors, which fit their inclinations, directions, aptitudes, and abilities.

- Consult and guide the students who wish to change their academic majors.

\section{References}

Abulaish, S. H. (2014). Counseling needs for female students at the Faculty of education at Hail University. The Arab journal for talent development, 5 .

Al-Asfoor, L. B. D. B. H. (2004). The consulting needs of secondary school students in Muscat and Al-Daqiliah areas, Sultanate of Oman. An analytical and descriptive study, master thesis, Sultan Qaboos University, Faculty of Education, Department of psychology science.

Al-Dlaim, F. A. (2011). Reality benefit from consulting services in the Saudi universities. Saudi Journal of higher education, $6^{\text {th }}$ issue.

Al-Hakamani, N. A. (2008). Consulting needs from the perspective of private University students in Sultanate of Oman. unpublished Master thesis, Yarmouk University, Irbid, Jordan.

Alrewily, F. F. (2010). The consulting needs of technical college students in the Kingdom of Saudi Arabia. Master thesis, Mutah University, Jordan.

Al-Reyashi, S. M. (2004). The consulting needs of community colleges and vocational colleges, and the proposed methods to satisfy it, Master thesis, Yemen.

Al-Shawi, S. S. (2012). Consulting needs and its relationship with the academic achievement motivation in physical education college for girl students. Contemporary sport magazine, 11(16).

Al-Swailem, I. (2002). Students' guiding and counseling, Riyadh, Dartwaiq for publishing and distribution.

Al-Tahan, M., \& Abu-Eita, S. (2002). The consulting needs of students at Hashemite University. Dirasat for educational and scientific studies, 1(29), 154-129

Donohue, D. M. (2014). Implementing School Wide Positive Behavioral Interventions and Supports (SWPBIS): School Counselors' Perceptions of Student Outcomes, School Climate, and Vocational Effectiveness. Doctoral Dissertations, Paper, 436.

Erford, B. T., House, R., \& Martin, P. (2011). Transforming the school counseling profession, Pearson Merrill/ Prentice Hall.

Fogel, A., \& Melson, E. (2004). Counseling Needs Importance in Applied Technical Colleges. Personal Guidance Journal, 45(3), 263-369.

Galassi, J. P., \& Akos, P. (2012). Preparing school counselors to promote academic development, Counselor Education and Supervision, 51(1), 50-63. https://doi.org/10.1002/j.1556-6978.2012.00004.x

Good, G. (1973). Dictionary of Education, New York, McGraw Hill.

Guneri, Y., Ayd, G., \& Shovholt, T. (2003). Counseling needs of students and evaluation of counseling services at a large urban university in Turkey. International Journal for advanced of counseling, 25(1), 53-63. https://doi.org/10.1023/A:1024928212103

Hatch, T. A. (2008). Vocational Challenges in School Counseling: Organizational, Institutional, and Political, Journal of 
School Counseling, 6(22), 22.

Kaufman, R. (1972). Educational System Planning. New Jersey, Prentice Hall.

Kolone R. L. S., Kolone, R. L. S., Karen M. P., \& Christine, P. C. (2006). The Relationship of Career Decision-Making Self-Efficacy, Vocational Identity, and Career Exploration Behavior in African American High School Students, Journal of Career Development, September, 33(1), 19-28.

Lapan, R. T., Gysbers, N. C., Stanley, B., \& Pierce, M. E., (2012). Missouri vocational school counselors: Ratios matter, especially in high-poverty schools, Vocational School Counseling, 16(2), 108-116. https://doi.org/10.5330/PSC.n.2012-16.108

Mansy, H., \& Mansy, E. (2004). The psychological guiding and counseling and its theories. $1^{\text {st }}$ edition, Dar Al-Kindi for publishing and distribution, Amman, Jordan

Milhem, S. M. (2007). Principles of psychological guiding and counseling. $1^{\text {st }}$ edition, Dar Al-Massira for publishing, distribution, and printing, Amman, Jordan.

Morsi, S. A. Al-H. (1997). The psychological counseling and educational and vocational guiding. Cairo, Elkhangy library.

Nicole, G. D. (2015). A Delphi Study: How Counselor Educators in Career Counseling Courses Prepare School Counselors to Address Career Readiness. Doctoral Dissertations, Paper, 715.

Nuri, A. M., \& Yahiya, A. M. (2008). The consulting needs (Social, psychological, academic) at Mosul University students. Journal of education and science, 15(3).

REDA, A. (2006). The integrated development of University student's personality and its role in raising the level of academic performance, vocational experimental research submitted to the twenty-seventh Conference of Arabic Organization for the staff of acceptance and enrollment in the universities of Arabic countries, University of Sharjah.

Sanatos, S. (2003). Goal instability, self-esteem, and vocational identity of high school Portuguese students. An.lise Psicol.gica, 21(2), 229-238. https://doi.org/10.14417/ap.112

Tashtoush, R. (2012). Indicative needs among students in the preparatory year at Al-Qassim University. Gulf and Arabic studies magazine, 38(146), 279-320.

\section{Copyrights}

Copyright for this article is retained by the author(s), with first publication rights granted to the journal.

This is an open-access article distributed under the terms and conditions of the Creative Commons Attribution license (http://creativecommons.org/licenses/by/4.0/). 